\title{
KERATOMETRY AND POST-OPERATIVE ASTIGMATISM
}

\author{
G. P. MISSON \\ Birmingham
}

\begin{abstract}
SUMMARY
Total post-operative refractive astigmatism and keratometric corneal astigmatism were determined in patients following cataract surgery. By comparing the results of the two methods, the value of keratometry as a simple and quick procedure for identification of surgically induced astigmatic errors was established. It is proposed that this method should be used before final refraction in an attempt to increase clinic efficiency and reduce further appointments resulting from surgically induced astigmatism.
\end{abstract}

A frequent complications of cataract extraction is surgically induced astigmatism ${ }^{1}$. This is predominantly corneal although other factors may contribute such as intraocular lens decentration and tilt. ${ }^{2}$ In the majority of cases the astigmatism is amenable to correction by selective suture removal. ${ }^{3}$

In many units it is routine for post-operative cataract patients to be sent to non-hospital based optometrists for refraction. If patients are not refracted in clinic, detection of high astigmatism requires further out-patient appointments thereby reducing clinic efficiency.

The purpose of this study was to determine the value of keratometry as a screening method for high degrees of astigmatism following cataract surgery. The total astigmatism determined by refraction was compared with corneal astigmatism determined by keratometry.

As a result of the relationship between irregular suture tension and corneal astigmatism, this study further assesses the role of keratometry in identification of tight sutures requiring removal.

\section{PATIENTS AND METHODS}

A randomly selected sample of 77 eyes of 69 patients was taken at six to eight weeks following extracapsular cataract surgery and posterior chamber intraocular lens implantation. Cataract surgery was performed by the consultants and resident staff at the Birmingham and Midland Eye Hospital and Selly Oak Hospital, Birmingham. Of the

Birmingham \& Midland Eye Hospital, Church Street, Birmingham B3 2NS.

Correspondence to: Mr. G. P. Misson, FCOphth, Birmingham and Midland Eye Hospital, Church Street, Birmingham B3 ZNS. eyes studied, 36 had corneal sections and 41 limbal sections with fornix based conjuctival flaps. Although there was some individual variation in technique, sections were closed with interrupted 10/0 monofilament nylon in all cases. Patients were excluded from the study if: corrected visual acuity in the study eye was worse than $6 / 12$; they were unable to fixate the keratometer or autorefractometer target; media opacities were present which interfered with refraction.

Objective refraction using a Canon R-20 autorefractometer preceded subjective refraction. Refractive astigmastism was expressed in terms of positive cylinder.

Keratometry, using a Carl Zeiss Jena Ophthalmometer Model 110, was performed immediately after subjective refraction without prior knowledge of the refraction result. The axis and power of refractive astigmatism were compared with the dioptric difference between maximum and minimum keratometric corneal powers and the axis of maximum power. Axis data was excluded if the astigmatic power was less than 0.25 dioptre. To facilitate analysis, astigmatic axes were expressed in terms of similar magnitude. For example, if an eye with a refractive cylindrical axis of $5^{\circ}$ had an axis of maximum corneal curvature of $175^{\circ}$, the former would be converted to $185^{\circ}$. The study involves comparison of measurements from two instruments both of which are suceptible to error. Correlation and regression analyses therefore have to take such errors into account so Lee's intra-class correlation coefficient and Deming's method of linear regression analysis were used.

\section{RESULTS}

The results of 77 eyes studied are summarised in Table I. Figures 1 and 2 are scatter diagrams of keratometric $v s$ refractive cylindrical axes and positive powers.

Table I Summary of results

\begin{tabular}{llclc}
\hline & \multicolumn{2}{c}{ Refraction } & \multicolumn{2}{c}{ Keratometry } \\
& cyl & axis & cyl & axis \\
\cline { 2 - 5 } mean & 2.925 & 104.23 & 2.808 & 107.8 \\
sd & 2.059 & 50.32 & 2.066 & 52.3 \\
$\min$ & 0 & 5 & 0 & 5 \\
$\max$ & 9.5 & 185 & 8.25 & 214 \\
$\mathrm{n}$ & 77 & 74 & 77 & 74 \\
\hline
\end{tabular}




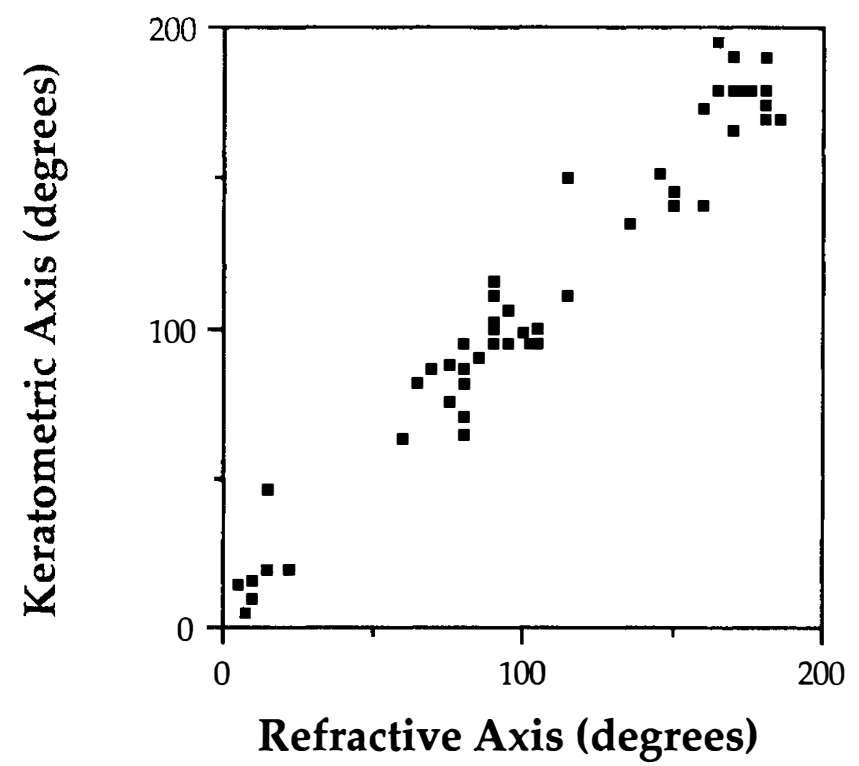

Fig. 1 Scatter diagram of axis of corneal astigmatism determined by keratometry against axis of total astigmatism determined by refraction.

No statistically significant difference was found between cylindrical power (Paired $t$-test; $t=0.354$, $\mathrm{p}=0.724)$ and axis $(\mathrm{t}=0.562, \mathrm{p}=0.574)$ in the two test groups. Correlation of the magnitude of keratometric versus refractive axes and cylindrical power were strong: for refractive $v s$ keratometric axes $\mathrm{r}=0.9749$; for refractive $v s$ keratometric powers $\mathrm{r}=0.8686$ (Table II).

When divided into categories according to section, the corneal group had a higher mean refractive astigmatic error $(3.21 \pm 2.44 \mathrm{sd})$ than the limbal group $(2.81 \pm 1.67 \mathrm{sd})$ : this difference was not statistically significant $(t=0.831, p=0.41)$. Furthermore there was no statistically significant difference between the intra-class

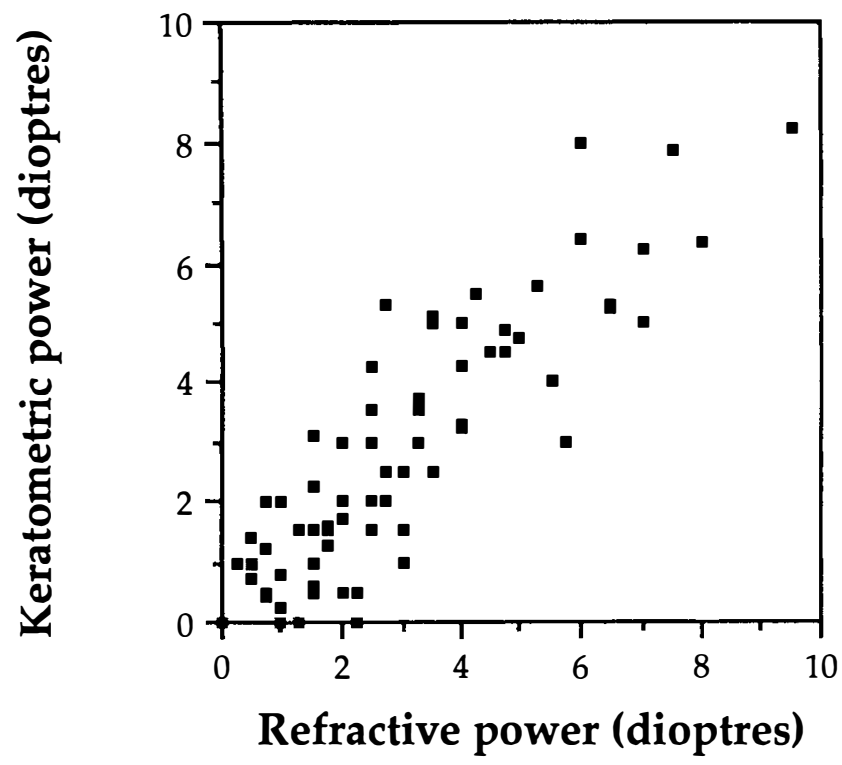

Fig. 2. Scatter diagram of power of corneal astigmatism determined by keratometry against power of total astigmatism determined by refraction. correlation of refractive and keratometric axis and cylinder between the two groups.

\section{DISCUSSION}

Astigmatism following cataract surgery with intraocular lens implantation may result from several causes. Intraocular lens position is theoretically important but investigations of optical aberrations of decentred and tilted intraocular lenses have shown the effects to be small. ${ }^{4}$ In those cases where high degrees of astigmatism result from lens displacement, abnormalities of lens position will be readily detected by slit-lamp biomicroscopy.

The principal cause of post-operative astigmatism is surgically induced corneal distortion. Therefore keratometry should be a convenient method of determining large post-operative astigmatic errors. Furthermore, keratometers are present in most units where pre-operative biometry is performed and their use requires less skill and time than conventional refraction.

This study is based on a comparison of readings from two instruments. The stastitical analysis of such data has been dealt with in detail by Bland and Altman ${ }^{5}$ who indicated that the familiar Pierson product moment correlation coefficient is inappropriate as it assumes that the independent variable is measured without error. A similar assumption is made if linear regression analysis is performed using the least squares method. Lee's Intraclass correlation and Deming's linear regression analysis take imprecision of the independent variable into account and are therefore the analyses of choice in this study. ${ }^{6}$

From the results presented here, it is apparent that determination of post-operative corneal astigmatism by keratometry correlates well with the total astigmatism as determined by refraction and did not differ statistically from it. The higher correlation for axial data may result from several factors. The corneal dioptric powers determined by keratometry are calculated values based on central corneal curvatures, a uniform corneal refractive index and the assumption that the cornea is a perfect sphere: they are therefore approximate. The posterior corneal curvature can influence ocular refraction ${ }^{7}$ and its surgical distortion may further contribute to post-operative refractive astigmatism.

In phakic patients, residual astigmatism (i.e. non-corneal astigmatism) is thought to result principally from asymmetry and displacement of the crystalline lens. ${ }^{8}$ The

Table II Correlation of keratometric and refractive axes and powers

\begin{tabular}{lccc}
\hline & $\begin{array}{c}\text { Cylinder Axes } \\
\text { KAx* v RAx }\end{array}$ & $\begin{array}{c}\text { Cylinder Powers } \\
\text { KvA }\end{array}$ \\
\cline { 3 - 4 } & $\mathrm{r}$ & 0.9749 & 0.8686 \\
& $\mathrm{t}$ & 35.8648 & 14.3516 \\
& $\mathrm{p}$ & $<0.0001$ & $<0.0001$ \\
Deming slope & & 0.9588 & 0.8529 \\
Intercept & & 0.6063 & 0.4133 \\
\hline
\end{tabular}

* KAx: Axis of greatest keratometric power

RAx: Axis of positive refractive cylinder

$\mathrm{K}$ : Difference of $\max$ and min keratometric powers

A: $\quad$ Power of refractive cylinder 
posterior corneal surface and rotation of the eye through angle alpha ${ }^{9}$ are thought to contribute to a lesser extent. By replacing the crystaline lens with a perfect spherically surfaced intraocular lens implant with little significant lens tilt, the main factor causing residual astigmatism is removed. In this situation, refractive astigmatism induced by deformation of the anterior corneal surface predominates. Therefore the high correlations between refractive and keratometric data found in this study may be expected.

Although not sufficiently accurate to quantify the magnitude of astigmatism for refractive purposes, the determination of astigmatic axis by keratometry correlates strongly with that of conventional refraction. The results of this study indicate that keratometry can be accurately used in identifying tight sutures requiring removal.

It is suggested that keratometry be performed in order to detect patients with large post-operative astigmatic errors before discharge to peripheral optometrists. Once identified, routine refraction may be performed and sutures adjusted as appropriate.

I wish to thank Dr. M. C. M. Dunne and Mr. P. I. Murray for criticism of the manuscript and Mr. D. E. Shaw for statistical assistance.
Key words: Cataract surgery, Keratometry, Post-operative Astigmatism, Refraction.

\section{REFERENCES}

1. Roper-Hall MJ: Control of astigmatism after surgery and trauma. Br J Ophthalmol 1982, 66: 556-9.

2. Jaffe NS: Cataract surgery and its complications. St Louis: Mosby, 1976; 83-98.

3. Atkins AD and Roper-Hall MJ: Control of postoperative astigmatism. Br J Ophthalmol 1985, 69: 348-51.

4. Lakshminarayanan V, Enoch JM, Raasch T, Crawford B, Nygaard RW: Refractive changes induced by intraocular lens tilt and longitudinal displacement. Arch Ophthalmol 1986, 104: 90-2.

5. Bland JM and Altman DG: Statistical methods for assessing agreement between two methods of clinical measurement. Lancet 1986, i: 307-10.

6. Smith DS, Pourfarzaneh M, Kamel RS: Linear regression analysis by Deming's method. Clin Chem 1980, 26: 1105-6.

7. Dunne MCM, Royston JM, Barnes DA: The influence of the posterior corneal surface upon total corneal astigmatism. Opt Vis Sci 1990, 67: 55

8. Tscherning M (trans Weiland C): Physiologic Optics. 1904; Keystone, Philadelphia.

9. Dunne MCM and Barnes DA: Modellng angle alpha. Ophthal Physiol Opt 1989, 9: 322-33. 